\title{
Trace elements and oxidative stress status in patients with psoriasis
}

\author{
Adnan Kirmit ${ }^{1}$, Saadet Kader ${ }^{2}$, Mustafa Aksoy³ ${ }^{3}$ Ceylan Bal ${ }^{4}$, Cemil Nural $^{4}$, Oruç Aslan ${ }^{1}$ \\ 'Department of Biochemistry, Faculty of Medicine, Harran University, Sanliurfa, Turkey \\ 2Department of Biochemistry, Karapinar State Hospital, Konya, Turkey \\ ${ }^{3}$ Department of Dermatology, Faculty of Medicine, Harran University, Sanliurfa, Turkey \\ ${ }^{4}$ Department of Biochemistry, Faculty of Medicine, Yıldırım Beyazıt University, Ankara, Turkey
}

Adv Dermatol Allergol 2020; XXXVII (3): 333-339

DOI: https://doi.org/10.5114/ada.2020.94265

\begin{abstract}
Introduction: Psoriasis is a common, inflammatory skin disease of which etiopathogenesis is still not explained clearly, however in which trace elements and oxidative stress are considered to play a role.

Aim: To evaluate the serum trace element and oxidative stress levels in patients diagnosed with psoriasis.

Material and methods: A total of 87 psoriasis patients and 60 healthy subjects were included in the study. Serum sodium ( $\mathrm{Na}$ ), potassium $(\mathrm{K})$, calcium $(\mathrm{Ca})$, phosphorus $(\mathrm{P})$, magnesium $(\mathrm{Mg})$, iron (Fe), selenium (Se), zinc ( $\mathrm{Zn})$, copper (Cu) levels, oxidative stress parameters, ischemia-modified albumin (IMA), catalase (CAT), myeloperoxidase (MPO) and ferroxidase (FOX) activity and an inflammatory marker, C-reactive protein (CRP), were examined in all participants.

Results: IMA, IMA/Albumin (IMA/Alb), CAT, Cu, FOX and CRP levels were found to be significantly higher; Se, Zn and albumin levels were significantly lower in the patient group as compared to the control group. No significant difference was found between groups with regard to $\mathrm{Na}, \mathrm{K}, \mathrm{Ca}, \mathrm{P}, \mathrm{Mg}$, Fe and MPO levels.

Conclusions: Some trace element levels and oxidant-antioxidant balance were changed in psoriasis patients.
\end{abstract}

Key words: trace element, selenium, zinc, copper, psoriasis, ischemia-modified albumin.

\section{Introduction}

Psoriasis is an inflammatory, proliferative and chronic skin disease with an incidence of $2-3 \%$ worldwide and is characterized by remission and recurrences. It is clinically characterized by silvery-white crust-coated erythematous plaques [1]. The disease is considered to have a genetic tendency and caused by triggering factors like trauma, infection, drug and stress. Pathogenesis of the disease is still not clearly explained although an ample amount of studies have been conducted for a long time [2]. The common idea is that inflammation triggered by oxidative stress plays a role in etiopathogenesis $[3,4]$. On the other hand, another hypothesis proposes that psoriasis arises from reactive oxygen species (ROS) production due to over-expression of pro-inflammatory cytokines [5, 6].

C-reactive protein (CRP) is an acute phase protein released from the liver in response to interleukin-6 (IL-6) and a sensitive inflammation marker [7]. CRP was reported to be able to be used as an inflammation marker in many conditions like psoriasis, rheumatoid arthritis, atopic dermatitis, cancer and cardio-vascular diseases $[7,8]$.

While free radicals have useful functions like protection from infections, killing of cancer cells and detoxification of xenobiotics when in normal ranges, they tend to show harmful effects through structural changes on lipids, proteins and nucleic acids when their levels are high $[9,10]$. Oxidative stress is a process which triggers inflammation. It was reported to play a role in etiopathogenesis of many skin diseases including psoriasis. Myeloperoxidase (MPO) shows microbicidal effects by forming ROS during degranulation of activated polymorphonuclear leukocytes (PMNL). However, when excessive ROS occurs in this way, it can cause tissue damage, lipid peroxidation and increased systemic oxidative stress [11]. Cutaneous accumulation of neutrophils was shown in psoriasis patients in many studies [12]. Therefore, the MPO level may be helpful in etiopathogenesis of psoriasis as it is the biomarker of neutrophil/monocyte activation $[12,13]$.

Address for correspondence: Dr. Adnan Kirmit, Department of Biochemistry, Faculty of Medicine, Harran University, 63290 Sanliurfa, Turkey, phone: +90 4143444444 (4138), fax: +90 414344 4000, e-mail: adnankirmit@yahoo.com Received: 14.02 .2020 , accepted: 3.03.2020. 
Metalloproteins may be helpful in investigating the aetiology as they play a role in oxidant-antioxidant mechanisms. The increase in oxidants triggers the activation of anti-oxidant defence mechanisms. Enzymatic antioxidant defence mainly includes glutathione peroxidase (GP), superoxide dismutase (SOD) and, catalase (CAT) [4]. However, MPO and CAT compete for $\mathrm{H}_{2} \mathrm{O}_{2}$ use. In addition, many inflammatory respiratory tract diseases were reported to be related with abnormal MPO/CAT ratios [14]. CP also shows anti-oxidant-like ferroxidase activity (FOX), it plays an important role as free oxygen radical scavenger [15]. The ceruloplasmin level may be an indicator related with the inflammatory process. Despite many studies investigating trace element levels in psoriasis, a limited number of studies have focused on the role of metal-binding proteins in psoriasis.

Trace elements are essential for biochemical processes in the body and play a role in immunologic and inflammatory reactions. However, keratinization and melanin formation are enzyme-dependent processes and may be affected by deficiencies or excesses of trace elements [16]. While SOD contains copper (Cu) and zinc (Zn) as a cofactor, GP contains selenium (Se) [17]. So Cu, Zn and Se contribute to elimination of free radicals through antioxidant enzyme systems [12]. However the studies on the role of trace elements and anti-oxidant enzymes in etiopathogenesis of psoriasis have revealed conflicting results. Levels of Cu, Zn, Se, SOD, GP and CAT were found to be high in some studies, low in some and unchanged in others $[5,18-24]$.

\section{Aim}

The aim of this study is to contribute a little bit to the elucidation of the etiopathogenesis of psoriasis with a relatively large number of patients and a broad range of biomarkers. Therefore, we evaluated the levels of CRP (as a biomarker of inflammation), ischemia-modified albumin (IMA), FOX, MPO, CAT (as indicators of oxidative stress) and trace elements (Cu, Zn, Se, Fe, Mg, Na, K, Ca, P) in psoriasis patients.

\section{Material and methods}

A total of 147 participants including 87 psoriasis patients and 60 healthy individuals who were matched for age and gender and did not have any systemic or skin diseases and were admitted to the dermatology clinic of the hospital between November 2017 and April 2018 were included in the study. The study was approved by the local ethics committee. Written informed consent form was obtained from all participants prior to the study. Diagnosis of psoriasis was made based on clinical findings and/or histopathology reports. The psoriasis patients who were under treatment (who had received any systemic or local therapy within the last month), pregnant or lactating women and the patients who had diabetes mellitus, hypertension, psychiatric disorders, cardiac problems and skin diseases other than psoriasis were excluded from the study.

Disease severity was determined based on the involved body area. According to this, involvement of $<3 \%, 3-10 \%$ and $>10 \%$ of the body was classified as mild, moderate and severe disease, respectively.

Venous blood samples were obtained from the antecubital vein of the participants, centrifuged at $3500 \mathrm{rpm}$ for 5 min after being stored at room temperature for $30 \mathrm{~min}$ and sera were transferred into Eppendorf tubes and stored at $-80^{\circ} \mathrm{C}$ until the day of analyses.

Levels of $\mathrm{Na}$ and $\mathrm{K}$ were measured with the ion selective electrode method; Ca, P, Mg, Fe and CRP levels were measured spectrophotometrically with auto-analyser (Architect c8000, Abbott, Illinois, USA) and with the same brand of device using kits.

Serum Se, Cu, Zn levels were measured with the atomic absorption spectrometer (Thermo ICE 3000, Tokyo, Japan). Serum Cu and Zn levels were measured with deuterium background correction by using the flame atomic absorption spectrometer; the selenium level was measured with Zeeman background correction by using the electro-thermal atomic absorption spectrometer. Standard Cu, Zn and Se solutions were prepared by dilution of certified standard solutions (high purity standards, Charleston, SC, USA). Two level quality control material (Seronorm, Billingstad; Norway) was used. Samples were diluted with $1 \%(1.10)$ nitric oxide $\left(\mathrm{HNO}_{3}\right)$. Standards were measured in the ranges of 0.05-1 ppm, 0.1-0.5 ppm and 2.5-25 ppb for $\mathrm{Cu}, \mathrm{Zn}$ and Se, respectively.

An ischemia-modified albumin (IMA) level was analysed by using an albumin cobalt binding test. $50 \mu \mathrm{l}$ of $0.1 \%$ cobalt (II) chloride $\left(\mathrm{CoCl}_{2}, 6 \mathrm{H}_{2} \mathrm{O}\right)$ (Sigma, Aldrich, Germany) was added to patient serum and incubated for 10 min for albumin's binding cobalt following the mixing procedure. Afterwards, $50 \mu \mathrm{l}$ of $1.5 \mathrm{mg} / \mathrm{ml}$ ditiotreitol was added and incubated for 2 min after the mixing procedure and $1 \mathrm{ml}$ of $0.9 \% \mathrm{NaCl}$ solution was added for reducing binding capacity. Blind solution was prepared with the same method but by using distilled water instead of ditiotreitol. Absorbance of the samples was measured spectrophotometrically (Varioskan LUX Multimode Microplate Reader) at $470 \mathrm{~nm}$. Results were expressed as $\mathrm{mg} / \mathrm{dl}$.

Catalase (CAT) activity was measured by using the method described by Goth [25]. According to this method, $0.2 \mathrm{ml}$ of the sample is added into $1 \mathrm{ml}$ substrate ( $65 \mathrm{\mu mol} \mathrm{H} \mathrm{O}_{2}, 60 \mathrm{mmol} / /$ sodium-potassium phosphate buffer $\mathrm{pH} 7.4$ ) and incubated at $37^{\circ} \mathrm{C}$ for $60 \mathrm{~min}$. Enzymatic reaction is stopped with $1 \mathrm{ml} 32.4 \mathrm{mM}$ ammonium molybdate. The yellow complex composed of molybdate and $\mathrm{H}_{2} \mathrm{O}_{2}$ is read against blank at $405 \mathrm{~nm}$.

Serum MPO activity was measured by using the modified form of the method described by Bradley. This 
measurement is based on absorbance at $460 \mathrm{~nm}$ proportionally with the amount of yellowish-orange product formed with the oxidation of o-dianisidine with MPO in the presence of hydrogen peroxide [26].

Ferroxidase activity levels were measured with the method described by Erel [27]. This method is automatic and colorimetric and is based on the enzymatic oxidation of the iron ion to the ferric ion.

\section{Statistical analysis}

Data were evaluated by using SPSS 21 (SPSS, Chicago, IL, USA) software program. The association between two groups with regard to gender was evaluated with $\chi^{2}$ test. Normality distribution of continuous variables was evaluated with Kolmogorov-Smirnov test. For comparison of mean values between two groups, normally distributed data were evaluated with independent sample $t$ (Student's t) test and the non-normally distributed data were evaluated with Mann-Whitney $U$ test. For detection of the correlation between the continuous variables, Pearson test was used for normally distributed data and Spearman correlation analysis was used for the data not normally distributed. ANOVA test was used to evaluate the differences between the means of continuous variables in the severity groups. Kruskal Wallis test was used to evaluate the differences between the means of non-parametric continuous variables in the severity groups. A $p$-value of $<0.05$ was accepted as statistically significant.

\section{Results}

A total of 147 participants (87 patients and 60 healthy individuals) were included in the study. The parameters showed a normal distribution except the disease duration (DD), body mass index (BMI) and CRP. Patient and control groups were similar with regard to gender, age and BMI (Table 1).

While an increase was detected in CRP, IMA, IMA/Alb, $\mathrm{Cu}, \mathrm{CAT}$ and FOX levels in the patient group as compared to the control group; Alb, Se and Zn levels were found to decrease and $\mathrm{Na}, \mathrm{K}, \mathrm{Ca}, \mathrm{P}, \mathrm{Fe}, \mathrm{Mg}$ and MPO levels were found not to change (Table 2).

When mean differences of continuous variables were analysed between disease severity groups, a significant difference was found only for FOX (ANOVA, $p=0.004$ ) and disease duration (ANOVA, $p=0.009$ ) (Table 3). In addition, a difference was found between CRP median values (Kruskal Wallis, $p=0.045$ )

The correlations between oxidative stress parameters, trace elements and CRP are presented in Table 4.

A positive correlation was found between $\mathrm{Cu}$ and oxidative stress parameters CRP, IMA and IMA/ALB; and a negative correlation was found between $\mathrm{Cu}$ and albumin and CAT (Table 5). A positive correlation was found between $\mathrm{Zn}$ and oxidative stress parameters; and a negative correlation was found with CAT (Table 5).
Table 1. Comparison of demographic characteristics between patient and control groups

\begin{tabular}{|c|c|c|c|}
\hline Parameter & Patient group & Control group & $P$-value \\
\hline Gender $(M / F)^{x^{2}}$ & $47 / 40$ & $26 / 34$ & 0.255 \\
\hline Age [year] ${ }^{\top}$ & $32.75 \pm 15.64$ & $30.80 \pm 12.89$ & 0.428 \\
\hline DD [year] & $7(0-37)$ & & \\
\hline BMI $\left[\mathrm{kg} / \mathrm{m}^{2}\right]^{\#}$ & $24.22(12.76-44.92)$ & $23.23(16.90-34.37)$ & 0.692 \\
\hline
\end{tabular}

Table 2. Comparison of mean values of continuous variables between patient and control groups ${ }^{\top}$

\begin{tabular}{lccc}
\hline Parameter & Patient group & Control group & $P$-value \\
\hline CRP $[\mathrm{mg} / \mathrm{dl}]^{\#}$ & $0.02(0.02-5.99)$ & $0.02(0.02-1.85)$ & $0.04^{*}$ \\
\hline $\mathrm{Se}[\mu \mathrm{g} / \mathrm{l}]$ & $76.68 \pm 22.86$ & $89.04 \pm 31.17$ & $0.006^{*}$ \\
\hline $\mathrm{Zn}[\mathrm{\mu g} / \mathrm{dl}]$ & $111.88 \pm 38.33$ & $131.41 \pm 39.72$ & $0.003^{*}$ \\
\hline $\mathrm{Cu}[\mu \mathrm{g} / \mathrm{dl}]$ & $118.73 \pm 41.67$ & $84.56 \pm 23.59$ & $<0.001^{*}$ \\
\hline $\mathrm{Na}[\mathrm{mEq} / \mathrm{l}]$ & $138.94 \pm 2.40$ & $138.41 \pm 2.15$ & 0.177 \\
\hline $\mathrm{K}[\mathrm{mEq} / \mathrm{l}]$ & $4.36 \pm 0.38$ & $4.36 \pm 0.29$ & 0.957 \\
\hline $\mathrm{Ca}[\mathrm{mg} / \mathrm{dl}]$ & $9.45 \pm 0.44$ & $9.49 \pm 0.42$ & 0.545 \\
\hline $\mathrm{P}[\mathrm{mg} / \mathrm{dl}]$ & $3.91 \pm 0.93$ & $3.87 \pm 0.58$ & 0.805 \\
\hline $\mathrm{Mg}[\mathrm{mg} / \mathrm{dl}]$ & $1.94 \pm 0.13$ & $1.98 \pm 0.12$ & 0.077 \\
\hline Fe $[\mu \mathrm{g} / \mathrm{dl}]$ & $92.01 \pm 34.92$ & $88.85 \pm 33.60$ & 0.585 \\
\hline IMA $\left[{ }^{\wedge} \mathrm{ABSU}\right]$ & $0.23 \pm 0.06$ & $0.18 \pm 0.05$ & $<0.001^{*}$ \\
\hline Albumin [g/dl] & $4.44 \pm 0.22$ & $4.58 \pm 0.25$ & $<0.001^{*}$ \\
\hline IMA $/ \mathrm{ALB}[\mathrm{AU}]$ & $0.052 \pm 0.017$ & $0.041 \pm 0.013$ & $<0.001^{*}$ \\
\hline CAT $[\mathrm{kU} / \mathrm{l}]$ & $135.5 \pm 21.2$ & $122.5 \pm 15.3$ & $<0.001^{*}$ \\
\hline $\mathrm{MPO}[\mathrm{U} / \mathrm{l}]$ & $107.82 \pm 33.51$ & $98.96 \pm 34.73$ & 0.123 \\
\hline FOX [U/l] & $503.79 \pm 85.64$ & $425.06 \pm 108.08$ & $<0.001^{*}$ \\
\hline
\end{tabular}

TStudent $t$ test, "Mann-Whitney $U$ test, " statistically significant difference. Median (minimum-maximum), mean $\pm S D,{ }^{\triangle} A B S U$ - absorbance unit, $A U-$ arbitrary unit, CRP - C-reactive protein, Se-selenium, $\mathrm{Zn}$ - zinc, Cu-copper, $\mathrm{Na}$-sodium, $\mathrm{K}$ - potassium, Ca-calcium, $P$ - phosphorus, $\mathrm{Mg}$ - magnesium, Fe - iron, IMA - ischemia-modified albumin, IMA/ALB - ischemia-modified albumin/albumin, CAT - catalase, MPO - myeloperoxidase, FOX-ferroxidase.

\section{Discussion}

An elevation was detected in CRP, IMA, IMA/Alb, Cu, CAT and FOX levels in the patient group and a decrease was detected in albumin, Se and Zn levels. Increased oxidative stress is one of the main theories proposed for the etiopathogenesis of psoriasis. Consistent with this, in this study, serum oxidative stress biomarker levels were higher in the patient group compared to the control group.

Ataş et al. have revealed that the elevation in serum IMA and the decrease in serum albumin were closely related with oxidative stress and the increase in oxidative stress could be an important sign in pathogenesis and 
Table 3. Mean differences of continuous variables between severity groups in psoriasis patients

\begin{tabular}{|c|c|c|c|c|}
\hline \multirow[t]{2}{*}{ Parameter } & \multicolumn{3}{|c|}{ Disease severity } & \multirow[t]{2}{*}{ ANOVA $p$} \\
\hline & Mild & Moderate & Severe & \\
\hline CRP $[\mathrm{mg} / \mathrm{dl}]$ & $0.02(0.02-5.99)$ & $0.7(0.02-4.39)^{\#}$ & $0.02(0.02-4.56)$ & $0.045^{K}$ \\
\hline Se $[\mu g / l]$ & $75.56 \pm 22.44$ & $77.10 \pm 24.12$ & $77.10 \pm 22.99$ & 0.962 \\
\hline $\mathrm{Zn}[\mu \mathrm{g} / \mathrm{dl}]$ & $120.46 \pm 42.98$ & $97.29 \pm 42.26$ & $114.28 \pm 31.87$ & 0.109 \\
\hline $\mathrm{Cu}[\mu \mathrm{g} / \mathrm{dl}]$ & $114.08 \pm 36.36$ & $129.78 \pm 42.60$ & $115.86 \pm 43.96$ & 0.377 \\
\hline IMA [ $\left.{ }^{\triangle} \mathrm{ABSU}\right]$ & $0.228 \pm 0.0526$ & $0.241 \pm 0.077$ & $0.227 \pm 0.0707$ & 0.713 \\
\hline Albumin [g/dl] & $4.47 \pm 0.21$ & $4.45 \pm 0.21$ & $4.415 \pm 0.2454$ & 0.582 \\
\hline IMA/ALB [AU] & $0.0513 \pm 0.0131$ & $0.0547 \pm 0.0185$ & $0.0522 \pm 0.0184$ & 0.789 \\
\hline CAT $[\mathrm{kU} / \mathrm{l}]$ & $138.44 \pm 20.89$ & $131.05 \pm 20.91$ & $136.08 \pm 21.66$ & 0.497 \\
\hline MPO [U/I] & $109.99 \pm 31.13$ & $108.42 \pm 36.56$ & $106.28 \pm 33.99$ & 0.908 \\
\hline FOX [U/I] & $463.45 \pm 77.74$ & $491.75 \pm 79.37$ & $532.87 \pm 83.83^{*}$ & 0.004 \\
\hline $\mathrm{DD}$ & $5.71 \pm 5.87$ & $7.24 \pm 8.37$ & $11.83 \pm 9.03^{¥}$ & 0.009 \\
\hline
\end{tabular}

${ }^{*}$ Between mild and severe $(p=0.012)$. ${ }^{*}$ Between mild and severe $(p=0.004)$. ${ }^{K}$ Kruskal Wallis. ${ }^{\# B e t w e e n ~ m i l d ~ a n d ~ m o d e r a t e ~}(p=0.015) .{ }^{4} A B S U-a b s o r b a n c e ~ u n i t$, $A U$ - arbitrary unit, CRP - C-reactive protein, Se - selenium, Zn - zinc, Cu - copper, IMA - ischemia-modified albumin, IMA/ALB - ischemia-modified albumin/ albumin, CAT - catalase, MPO - myeloperoxidase, FOX - ferroxidase, DD - disease duration.

Table 4. Significant correlations between some parameters in psoriasis patients

\begin{tabular}{llcccc}
\hline Parameter & $P$-value & $r$ & Parameter & $P$-value & $r$ \\
\hline Cu-IMA/ALB & $<0.001^{\Psi}$ & 0.503 & CRP-Cu & $<0.001^{\Omega}$ & 0.589 \\
\hline CU-CAT & $<0.001^{\Psi}$ & -0.714 & CRP-(IMA/ALB) & $<0.001^{\Omega}$ & 0.704 \\
\hline (IMA/ALB)-CAT & $<0.001^{\Psi}$ & -0.489 & CRP-CAT & $<0.001^{\Omega}$ & -0.530 \\
\hline IMA-ALB & $<0.001$ & -0.601 & & & \\
\hline
\end{tabular}

${ }^{\Psi}$ Pearson correlation test, ${ }^{\Omega}$ Spearman correlation analysis, $\mathrm{CU}$ - copper, IMA - ischemia-modified albumin, ALB - albumin, CAT-catalase, CRP-C-reactive protein.

prognosis [28]. Özdemir et al. have detected a significant inverse correlation between IMA and serum albumin levels [29]. Consistent with these, in this study, serum IMA and IMA/ALB ratio was found to be high and albumin levels were lower in patients with psoriasis compared to the control group $(p<0.001)$ (Table 2). There was also a significant negative correlation between IMA and albumin levels in the patient group $(p<0.001)$ (Table 4). However, no correlation was found between IMA, IMA/ Alb levels and severity of psoriasis. Elevated IMA levels support the assumption of increased oxidative stress in psoriasis.

Psoriasis is an inflammatory and proliferative disease of the skin [2]. C-reactive protein (CRP) is an acute phase protein released from the liver as response to IL- 6 and a sensitive inflammation marker [7]. Recent studies have reported an association between elevated CRP levels and prognosis of psoriasis [7, 8, 30]. CRP levels were found to be statistically significantly higher in the patient group compared to the healthy group also in this study ( $p<0.001)$. However, we found a slight correlation between CRP and the severity of psoriasis (Table 4). Increased levels of CRP support the background of inflammation in psoriasis.
Selenium is an important trace element which shows anti-proliferative and immune-modulatory effects. This active compound plays a role in protective redox reactions against oxidative damage, mainly due to being the cofactor of glutathione peroxidase $[6,31]$. Selenium deficiency is reported to be one of the risk factors which could lead to susceptibility to inflammatory skin diseases [31-33]. An ample amount of studies are available showing low serum Se concentration in psoriasis patients [6, 34, 35]. Kadry et al. have found that plasma Se levels were lower, osteopontin levels were extremely higher in the patient group compared to the control group and proposed that over-expression of osteopontin and low Se levels could be associated with the pathogenesis of psoriasis [36]. In the study of Seneczko, serum Se levels were shown to be significantly low beside erythrocytes in psoriasis patients as compared to controls [37]. We also detected that Se levels were lower in psoriasis patients as compared to controls ( $p=0.006)$.

Some researchers reported that serum $\mathrm{Zn}$ levels were extremely low in psoriasis patients [38-41]. However Ala et al. [5] and Kreft et al. [42] did not find a statistically significant difference between psoriasis patients and healthy controls with regard to Zn levels. In our study, Zn 
levels were found to be statistically significantly lower in the patient group as compared to the control group $(p<0.001)$ supporting the previous studies. In addition, our finding of the opposite relationship between $\mathrm{Zn}$ and CRP and IMA/ALB reveals that the level of $Z n$ decreases in oxidative stress (Table 5). It has been reported that there is a negative relationship between surface area involvement and the serum Zn level in psoriasis patients. This may be due to a decrease in serum Zn level causing an increase in skin involvement or a result of excessive skin exfoliation causing zinc loss [43].

Copper is related with several metalloproteins and one fraction in serum (5\%) binds to albumin loosely and another binds to globulin (ceruloplasmin) tightly [40]. As ceruloplasmin is an acute phase reactant and more than $90 \%$ of serum copper is transferred with ceruloplasmin, elevated Cu levels could only be an inflammation marker [40, 44]. Basavaraj et al. [18] evaluated Cu levels in psoriasis patients and found that serum Cu levels were higher in both mild and severe groups compared to the control group. Shahram Ala et al. found serum $\mathrm{Cu}$ levels higher in psoriasis patients compared to controls [5]. Similarly, in this study, Cu levels were higher in the patient group than in the control group $(p<0.001)$. There was also a positive correlation between $\mathrm{Cu}$ and CRP $(p<0.001, r=0.589)$. Therefore, this increase in $\mathrm{Cu}$ seems to develop secondarily to elevation of ceruloplasmin, the acute phase protein. Nevertheless, our finding of an opposite relationship between $\mathrm{Cu}$ and albumin levels supports the argument that the level of albumin decreases with increased inflammation.

Excessive Fe levels were shown in various skin pathologies like psoriasis which contain inflammatory responses $[45,46]$. Iron homeostasis was also shown to alter under oxidative stress conditions [45, 47]. Basavaraj et al. reported that serum Fe levels were lower both in mild and severe psoriasis patients compared to the control group [18]. In our study, although serum Fe levels were found to be higher in psoriasis patients compared to the control group, this difference was not statistically significant $(p=0.585)$.

Oxidative stress is among the main theories in psoriasis pathogenesis. Reactive oxygen species were reported to be responsible for angiogenesis in keratinocytes and uncontrolled transcription increase in psoriasis [48, 49]. CAT was found high in some studies [20, 23] and low in some others [21, 22]. In our study, a statistically significant increase was detected in CAT activity in the psoriasis group compared to the control group ( $p<0.001)$. However, there was a negative correlation between CAT and IMA/ALB ( $p<0.001, r=-0.489)$ (Table 4). Taken together, the increase in CAT levels seems to develop as a defence mechanism against the increase in oxidative stress.

Myeloperoxidase is an enzyme which is used by neutrophils to form anti-microbial reactive oxygen species
Table 5. Correlation analyses between trace elements and other parameters ${ }^{\Psi}$

\begin{tabular}{|c|c|c|c|c|}
\hline Parameter & & Se $[\mu \mathrm{g} / \mathrm{l}]$ & $\mathrm{Zn}[\mu \mathrm{g} / \mathrm{dl}]$ & $\mathrm{Cu}[\mu \mathrm{g} / \mathrm{dl}]$ \\
\hline \multirow[t]{2}{*}{$\mathrm{CRP}[\mathrm{mg} / \mathrm{dll}]^{2}$} & $r$ & -0.015 & $-0.253^{*}$ & $0.589^{\star *}$ \\
\hline & $p$ & 0.894 & 0.018 & 0.001 \\
\hline \multirow[t]{2}{*}{$\mathrm{Na}[\mathrm{mEq} / \mathrm{l}]$} & $r$ & 0.04 & 0.021 & 0.13 \\
\hline & $p$ & 0.712 & 0.845 & 0.229 \\
\hline \multirow[t]{2}{*}{$\mathrm{K}[\mathrm{mEq} / \mathrm{l}]$} & $r$ & -0.032 & -0.08 & 0.099 \\
\hline & $p$ & 0.77 & 0.46 & 0.363 \\
\hline \multirow[t]{2}{*}{$\mathrm{Ca}[\mathrm{mg} / \mathrm{dl}]$} & $r$ & 0.031 & 0.122 & -0.167 \\
\hline & $p$ & 0.774 & 0.259 & 0.121 \\
\hline \multirow[t]{2}{*}{$\mathrm{P}[\mathrm{mg} / \mathrm{dll}]$} & $r$ & -0.078 & -0.034 & $0.321^{\star *}$ \\
\hline & $p$ & 0.47 & 0.752 & 0.002 \\
\hline \multirow[t]{2}{*}{$\mathrm{Mg}[\mathrm{mg} / \mathrm{dl}]$} & $r$ & 0.12 & 0.169 & 0.041 \\
\hline & $p$ & 0.267 & 0.118 & 0.707 \\
\hline \multirow[t]{2}{*}{$\mathrm{Fe}[\mu \mathrm{g} / \mathrm{dl}]$} & $r$ & $0.248^{\star}$ & 0.103 & -0.207 \\
\hline & $p$ & 0.021 & 0.341 & 0.054 \\
\hline \multirow[t]{2}{*}{ IMA [ $\triangle \mathrm{ABSU}]$} & $r$ & 0.096 & -0.211 & $0.488^{* *}$ \\
\hline & $p$ & 0.377 & 0.05 & 0.001 \\
\hline \multirow[t]{2}{*}{ Albumin [g/dl] } & $r$ & 0.015 & 0.162 & $-0.404^{\star *}$ \\
\hline & $p$ & 0.893 & 0.134 & 0.001 \\
\hline \multirow{2}{*}{$\begin{array}{l}\mathrm{MA} / \mathrm{ALB} \\
{[\mathrm{AU}]}\end{array}$} & $r$ & 0.087 & $-0.213^{*}$ & $0.503^{\star *}$ \\
\hline & $p$ & 0.421 & 0.048 & 0.001 \\
\hline \multirow{2}{*}{ CAT [kU/l] } & $r$ & 0.08 & $0.280^{\star \star}$ & $-0.714^{\star *}$ \\
\hline & $p$ & 0.461 & 0.009 & 0.001 \\
\hline \multirow{2}{*}{ MPO [U/I] } & $r$ & 0.005 & 0.09 & -0.152 \\
\hline & $p$ & 0.967 & 0.405 & 0.159 \\
\hline \multirow{2}{*}{$\mathrm{FOX}[\mathrm{U} / \mathrm{I}]$} & $r$ & -0.055 & -0.011 & $0.394^{\star \star}$ \\
\hline & $p$ & 0.612 & 0.92 & 0.001 \\
\hline
\end{tabular}

${ }^{*}$ Correlation is significant at the 0.05 level (2-tailed). ${ }^{* *}$ Correlation is significant at the 0.01 level (2-tailed). "Pearson correlation test, ${ }^{\Omega}$ Spearman correlation analysis.

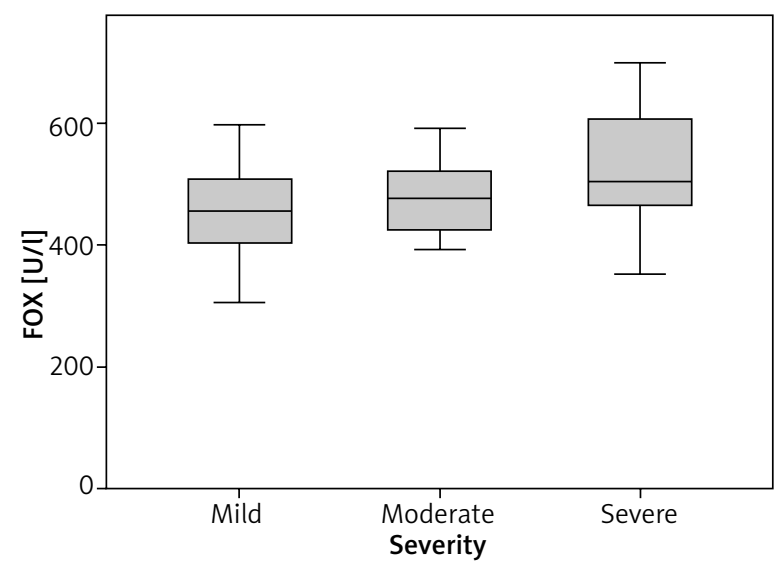

Figure 1. Ferroxidase (FOX) levels according to disease severity groups 
during phagocytosis. These oxidants kill the phagocytized bacteria, but when produced in excessive amounts, they also lead to tissue damage [50]. Yazıcı et al. found MPO levels higher than controls in psoriasis patients both in serum and the skin [12]. In our study, while MPO levels were found high, this difference was not statistically significant ( $p=0.123)$.

Serum ceruloplasmin levels are generally measured indirectly as FOX activity. Although ceruloplasmin levels may increase in physiologic conditions like pregnancy, they usually increase in chronic inflammatory diseases and the fact that these pathologic conditions are related with ROS production is striking [51]. Ceruloplasmin represents a protein with specific domains capable of both facilitating cellular energy production and preventing oxygen radical formation [52]. Perhaps ceruloplasmin is increasing to prevent oxidant formation. Matoshvili et al. found serum ceruloplasmin levels higher in psoriasis patients compared to controls [23]. Similarly, we also found FOX activity levels higher in the patient group as compared to the control group $(p<0.001)$. In addition, FOX activity showed a significant difference between disease severity groups as well ( $p=0.004$ ) (Table 3 , Figure 1 ). Ceruloplasmin is known to be an acute phase reactant. But perhaps the increase in psoriasis develops as a compensatory to oxidative stress.

We did not detect a significant difference between patient and control groups with regard to $\mathrm{Na}, \mathrm{K}, \mathrm{Ca}, \mathrm{P}$ and Mg levels.

The present study has some limitations. If we could measure the studied parameters not only in serum but also in urine, involved skin and uninvolved skin; and also if we could directly measure the oxidative stress level (like total oxidant status), we could make more reliable comments on the role of these parameters in etiopathogenesis of psoriasis.

\section{Conclusions}

The present study has indicated that there are alterations in serum trace element levels and an increase in inflammation and oxidative stress in psoriasis patients. Supplementation of Se and Zn, and anti-oxidant therapy could positively influence the clinical course of the disease. However more comprehensive studies are required to explain the role of these findings in etiopathogenesis of psoriasis.

\section{Conflict of interest}

The authors declare no conflict of interest.

\section{References}

1. Bidaki E, Zargari F, Mansouri P, et al. Lesion area assessment in psoriasis patients. J Med Eng Technol 2011; 35: 154-60.
2. Saraç G, Kapıcıoğlu Y. Psoriasisin Etyopatogenezi. Dermatoz 2015; 6: 1-4.

3. Naziroglu M, Yildiz K, Tamturk B, et al. Selenium and psoriasis. Biol Trace Elem Res 2012; 150: 3-9.

4. Armstrong A, Voyles S, Armstrong E, et al. Angiogenesis and oxidative stress: common mechanisms linking psoriasis with atherosclerosis. J Dermatol Sci 2011; 63: 1-9.

5. Ala S, Shokrzadeh M, Golpour M, et al. Zinc And copper levels in Iranian patients with psoriasis: a case control study. Biol Trace Elem Res 2013; 153: 22-7.

6. Wacewicz M, Socha K, Soroczynska J, et al. Concentration of selenium, zinc, copper, cu/zn ratio, total antioxidant status and C-reactive protein in the serum of patients with psoriasis treated by narrow-band ultraviolet $\mathrm{B}$ phototherapy: a case-control study. J Trace Elem Med Biol 2017; 44: 109-14.

7. Breuer K, Goldner FM, Jager B, et al. Relationship between chronic stress and CRP levels in women with psoriasis. J Dtsch Dermatol Ges 2016; 14: 528-30.

8. Isha, Jain VK, Lal H. C-reactive protein and uric acid levels in patients with psoriasis. Indian J Clin Biochem 2011; 26: 309-11.

9. Karabulut H, Gülay M. Free radicals. Makü Sag Bil Enst Derg 2016; 4: 50-9.

10. Birben E, Sahiner U, Sackesen C, et al. Oxidative stress and antioxidant defense. Wao J 2012; 5: 9-19.

11. Borawski J. Myeloperoxidase as a marker of hemodialysis biocompatibility and oxidative stress: the underestimated modifying effects of heparin. Am J Kidney Dis 2006; 47: 37-41.

12. Yazici C, Kose K, Utas S, et al. A novel approach in psoriasis: first usage of known protein oxidation markers to prove oxidative stress. Arch Dermatol Res 2016; 308: 207-12.

13. Heinecke J, Li W, Francis G, et al. Tyrosyl radical generated by myeloperoxidase catalyzes the oxidative cross-linking of proteins. J Clin Invest 1993; 91: 2866-72.

14. Ali I, Khan S, Chatzicharalampous C, et al. Catalase prevents myeloperoxidase self-destruction in response to oxidative stress. J Inorg Biochem 2019; 197: 110706.

15. El-Gharabawy R, Ahmed A, Al-Najjar A. Mechanism of action and effect of immune-modulating agents in the treatment of psoriasis. Biomed Pharmacother 2017; 85: 141-7.

16. Bock M, Schmidt A, Bruckner T, et al. Occupational skin disease in the construction industry. Br J Dermatol 2003; 149: 1165-71.

17. Kocyigit A, Erel O, Gur S. Effects of tobacco smoking on plasma selenium, zinc, copper and iron concentrations and related antioxidative enzyme activities. Clin Biochem 2001; 34: 629-33.

18. Basavaraj K, Darshan M, Shanmugavelu P, et al. Study on the levels of trace elements in mild and severe psoriasis. Clin Chim Acta 2009; 405: 66-70.

19. Bhatnagar M, Bapna A, Khare A. Serum proteins, trace metals and phosphatases in psoriasis. Indian J Dermatol Venereol Leprol 1994; 60: 18-21.

20. Yildirim $M$, Inaloz $H$, Baysal V, et al. The role of oxidants and antioxidants in psoriasis. J Eur Acad Dermatol Venereol 2003; 17: 34-6.

21. Thérond P, Gerbaud P, Dimon S, et al. Antioxidant enzymes in psoriatic fibroblasts and erythrocytes. I Invest Dermatol 1996; 106: 1325-31.

22. Gabr S, Al-Ghadir A. Role of cellular oxidative stress and cytochrome $\mathrm{C}$ in the pathogenesis of psoriasis. Arch Dermatol Res 2012; 304: 451-7.

23. Matoshvili M, Katsitadze A, Sanikidze T, et al. Alterations of redox-status during psoriasis. Georgian Med News 2014; 232-233: 60-4. 
24. Chen W, Zhou X, Zhu W. Trace elements homeostatic imbalance in psoriasis: a meta-analysis. Biol Trace Elem Res 2019; 191: 313-22.

25. Goth L. A simple method for determination of serum catalase activity and revision of reference range. Clin Chim Acta 1991; 196: 143-51.

26. Bradley P, Priebat D, Christensen R, et al. Measurement of cutaneous inflammation: estimation of neutrophil content with an enzyme marker. J Invest Dermatol 1982; 78: 206-9.

27. Erel O. Automated measurement of serum ferroxidase activity. Clin Chem 1998; 44: 2313-9.

28. Ataş H, Hacınecipoğlu F, Gönül M, et al. Antioksidan Enzim Ve Oksidatif Biyobelirteçlerin Psöriasiste Klinik Değeri. Okmeydanı Tıp Dergisi 2017; 33: 270-80.

29. Özdemir M, Kiyici A, Balevi A, et al. Assessment of ischaemia-modified albumin level in patients with psoriasis. Clin Exp Dermatol 2012; 37: 610-4.

30. Uysal S, Yılmaz F, Karatoprak K, et al. The levels of serum pentraxin3, CRP, fetuin-A, and insulin in patients with psoriasis. Eur Rev Med Pharmacol Sci 2014; 18: 3453-8.

31. Rayman M. The importance of selenium to human health. Lancet 2000; 356: 233-41.

32. Michaelsson G, Edqvist LE. Erythrocyte glutathione peroxidase activity in acne vulgaris and the effect of selenium and vitamin E treatment. Acta Derm Venereol 1984; 64: 9-14.

33. Mckenzie R. Selenium, ultraviolet radiation and the skin. Clin Exp Dermatol 2000; 25: 631-6.

34. Serwin A, Mysliwiec H, Hukalowicz K, et al. Soluble tumor necrosis factor-alpha receptor type 1 during selenium supplementation in psoriasis patients. Nutrition 2003; 19: 847-50.

35. Desilva B, Beckett G, Mclean S, et al. Lack of effect of oral selenite on P53 associated gene expression during tl01 therapy of psoriasis patients. Photodermatol Photoimmunol Photomed 2007; 23: 98-100.

36. Kadry D, Rashed L. Plasma and tissue osteopontin in relation to plasma selenium in patients with psoriasis. J Eur Acad Dermatol Venereol 2012; 26: 66-70.

37. Seneczko M. Selenium balance in patients suffering from psoriasis vulgaris in different development phases. Part 1. Concentration of selenium in selected morphotic components and excreta and activity of glutation peroxidase in red blood cells. Post Dermatol Alergol 2004; 21: 36-46.

38. Greaves M, Boyde T. Plasma-zinc concentrations in patients with psoriasis, other dermatoses, and venous leg ulceration. Lancet 1967; 2: 1019-20.

39. Mcmillan E, Rowe D. Plasma zinc in psoriasis: relation to surface area involvement. Br J Dermatol 1983; 108: 301-5.

40. Afridi H, Kazi T, Kazi N, et al. Evaluation of cadmium, chromium, nickel, and zinc in biological samples of psoriasis patients living in Pakistani cement factory area. Biol Trace Elem Res 2011; 142: 284-301.

41. Sheikh G, Masood Q, Majeed S, et al. Comparison of levels of serum copper, zinc, albumin, globulin and alkaline phosphatase in psoriatic patients and controls: a hospital based casecontrol study. Indian Dermatol Online J 2015; 6: 81-3.

42. Kreft B, Wohlrab J, Fischer M, et al. Analysis of serum zinc level in patients with atopic dermatitis, psoriasis vulgaris and in probands with healthy skin. Hautarzt 2000; 51: 931-4.

43. Nigam P. Serum zinc and copper levels and $\mathrm{Cu}: \mathrm{Zn}$ ratio in psoriasis. Indian J Dermatol Venereol Leprol 2005; 71: 205-6.

44. Hinks L, Young S, Clayton B. Trace element status in eczema and psoriasis. Clin Exp Dermatol 1987; 12: 93-7.
45. Forslind B, Werner-Linde $\mathrm{Y}$, Lindberg $\mathrm{M}$, et al. Elemental analysis mirrors epidermal differentiation. Acta Derm Venereol 1999; 79: 12-7.

46. Lee S, Tomasetto C, Sager R. Positive selection of candidate tumor-suppressor genes by subtractive hybridization. Proc Natl Acad Sci USA 1991; 88: 2825-9.

47. Pantopoulos K, Hentze M. Rapid responses to oxidative stress mediated by iron regulatory protein. EMBO J 1995; 14: 2917-24.

48. Halliwell B, Gutteridge JM. Free Radicals In Biology And Medicine. Oxford University Press, USA 2015.

49. Bito T, Nishigori C. Impact of reactive oxygen species on keratinocyte signaling pathways. I Dermatol Sci 2012; 68: 3-8.

50. Davies M, Hawkins C, Pattison D, et al. Mammalian Heme peroxidases: from molecular mechanisms to health implications. Antioxid Redox Signal 2008; 10: 1199-234.

51. Ganini D, Canistro D, Jang J, et al. Ceruloplasmin (ferroxidase) oxidizes hydroxylamine probes: deceptive implications for free radical detection. Free Radic Biol Med 2012; 53: 1514-21.

52. Harris Z. Ceruloplasmin. In: Clinical and Translational Perspectives on Wilson Disease: Kerkar N, Roberts E (eds.). Academic Press 2019; 77-84. 